\title{
Identification of Trichomonas Vaginalis Genotypes Using by Actin Gene and Molecular Based Methods in Southwest of Iran
}

\author{
Maryam Alikhani ${ }^{1,2}$, Reza Saberi ${ }^{3,4}$, Seyed Abdollah Hosseini ${ }^{3}$, Fatemeh Rezaei ${ }^{5}$, \\ Abdol Sattar Pagheh ${ }^{6}$, Asad Mirzaei*1,2
}

\begin{abstract}
Background: Trichomonas vaginalis (T. vaginalis) is a sexually transmitted protozoan parasite and the causative agent of trichomoniasis. The genetic characterization of $T$. vaginalis isolates shows notable genetic variation in this parasite. In the present study, we aimed to identify the T. vaginalis genotypes based on analyzing of actin gene in women specimens referred to health centers of Ilam city, southwest Iran.

Methods: A total of 1765 female samples were collected from gynecology clinics in the city of Ilam. DNA was extracted from positive samples and nested polymerase chain reaction (Nested PCR) was used to amplify the actin gene. Then, partial sequencing and genotyping of the actin gene was performed. A phylogenetic tree was drawn using the detected genotypes of T. vaginalis and reference sequences.

Results: Twenty-one of the 1765 urine and vaginal samples were positive for T. vaginalis. All infected individuals were married and their age in years was between 25 to 34. Further, the majority of infected women had cervical lesions, patchy erythema, and white color discharge. According to sequencing analysis, the isolates were identified as genotype $G(n=8)$ and genotype $E(n=2)$.

Conclusions: From the collected samples, we were able to distinguish at least two genotypes $(\mathrm{G}$ and E) of T. vaginalis. However, lesser is known about these genotypes in the city of Ilam. Further studies with a higher number of isolates should be performed in order to understand the implications of these results in this region.
\end{abstract}

Keywords: Actin gene, Genotypes, Ilam, Iran, Trichomonas vaginalis.

\section{Introduction}

Trichomonas vaginalis (T. vaginalis) is a flagellated protozoan or parasite that causes Trichomoniasis and exists primarily in the human urogenital tract (1). Trichomoniasis is a common sexually transmitted non-viral parasitic disease seen worldwide (2). The prevalence of $T$. vaginalis can vary based on geographical location, sex, individual health status and sociocultural factors (3). Recent reports of different countries estimate the prevalence of $T$. vaginalis to be between 3.9 and $24.6 \%$ (4). Furthermore, T. vaginalis is ten times more prevalent in women than men, for example, in America and Africa, approximately $20 \%$ of women and $2 \%$ of men had $T$. vaginalis (5). In Iran, the prevalence

1: Department of Medical Parasitology, Faculty of Allied Medical Sciences, Ilam University of Medical Sciences, Ilam, Iran.

2: Zoonotic Diseases Research Center, Ilam University of Medical Sciences, Ilam, Iran.

3: Toxoplasmosis Research Center, Department of Parasitology, School of Medicine, Mazandaran University of Medical Sciences, Sari, Iran.

4: Student Research Committee, Mazandaran University of Medical Sciences, Sari, Iran.

5: Islamic Azad University, Chalus Branch, Chalus, Iran.

6: Infectious Diseases Research Center, Birjand University of Medical Sciences, Birjand, Iran.

*Corresponding author: Asad Mirzaei; Tel: +989188416653; E-mail: mirzaei-as@medilam.ac.ir.

Received: 18 Dec, 2020; Accepted: 19 Jan, 2021 
was less than $1 \%$ in northern Iran and $39 \%$ in Tehran (6).

Due to antigenic variation and genetic diversity, different isolates of $T$. vaginalis may confer varying degrees of pathogenicity ranging from asymptomatic to severe vaginitis (7). Approximately 50\% of individuals with trichomoniasis are asymptomatic. However, in women, $T$. vaginalis can cause vaginitis, abnormal vaginal discharge, vulvar irritation, inflammation, abnormal pregnancy outcomes, and cervical neoplasia, whereas in men, symptoms include prostatitis dysuria, inflammation, urethritis, epididymitis and reversible infertility $(8,9)$.

Given the advances in molecular genetics and biotechnology, various $T$. vaginalis genotypes have been documented and have provided various clinical manifestations associated with this disease (10). Though many studies have extensively evaluated the genetic diversity of $T$. vaginalis in certain countries, these investigations should be extended to regions where this data is less characterized $(11,12)$.

In the past, researchers have used several tools to study the genetic properties of $T$. vaginalis, including Restriction Fragment Length Polymorphism (RFLP) (13), internal transcribed spacer analysis (ITS) (14), quantitative real-time PCR (15) and nucleotide sequencing (PCR sequencing) (16).

Interestingly, the actin gene was found to induce morphological changes and play a major role in the pathogenesis of $T$. vaginalis (17) making it an ideal candidate for targeted investigations on the molecular level, and genotyping (including PCR sequencing) (18).

Considering the increase in prevalence and severe health consequences associated with a $T$. vaginalis infection, the objective of this study was to determine the genotypes of $T$. vaginalis that circulates amongst women in Ilam city using PCR sequencing of the actin gene. Finally, this study could have real-life implications in epidemiological research, public health, and parasitic management.

\section{Materials and Methods \\ Ethical considerations}

In this investigation, all procedures including the collection of vaginal secretions and urine samples were approved by the Ethics Committee of Ilam University of Medical Sciences (number: 2015-124).

\section{Sample collection}

This cross-sectional study was conducted on 1765 women that were referred to gynecology clinics across the city of Ilam (southwest Iran) between July 2018 and December 2019. The demographic and clinical data of patients were collected using a questionnaire. Vaginal secretions were sampled individually from the posterior vaginal fornix using a sterile cotton swab (3). To detect trophozoites of $T$. vaginalis, wet mount smears of samples were prepared using normal saline and surveyed immediately under a light microscope. Moreover, $25 \mathrm{ml}$ of urine was collected for each patient in sterile urine containers and transported to the parasitology laboratory at the Ilam University of Medical Sciences. The samples were centrifuged at $2500 \mathrm{rpm}$ for 3 min and the pellet were used to prepare glass slides, Giemsa-staining and finally, microscopic investigation. For molecular examination, the urine sediment was washed three times with $0.5 \mathrm{ml}$ of phosphate buffered saline (PBS).

\section{DNA extraction and PCR amplification assay}

Total DNA extraction for each sample was performed using the DNG-plus ${ }^{\mathrm{TM}}$ kit according to the manufacturer's guidelines (Cinna Gene, Iran). The concentration and quality of extracted DNA was measured using a nanodrop instrument (Nano Drop Technologies, Wilmington, DE, USA). An $1100 \mathrm{bp}$ fragment of actin gene was amplified by Nested PCR. External primer included Tv8s (5'-TCT GGA ATG GCT GAA GAA GAC G - 3') and Tv9R (5'- CAG GGT ACA 
TCG TAT TGG TC-3) and internal primers: Tv10s (5' -CAG ACA CTC GTT ATC G-3') and Tv11R (5'- CGG TGA ACG ATG GAT G-3') (19). In the first amplification round, the $25 \mu \mathrm{l}$ reaction mixture contained $12.5 \mu \mathrm{l}$ Master mix RED (Ampliqon), $2 \mu$ template DNA, 10 pmol of each forward and reverse external primers $(2 \mu \mathrm{l})$, and $8.5 \mu \mathrm{l}$ doubledistilled water. The cycling conditions were $95{ }^{\circ} \mathrm{C}$ for $5 \mathrm{~min}, 30$ cycles of $95^{\circ} \mathrm{C}$ for 30 sec, $57^{\circ} \mathrm{C}$ for $45 \mathrm{sec}, 72{ }^{\circ} \mathrm{C}$ for $45 \mathrm{sec}$ and a final extension of $72{ }^{\circ} \mathrm{C}$ for $5 \mathrm{~min}$.

Nested PCR was performed using $1 \mu \mathrm{l}$ first-round PCR product as template DNA, 20 pmol of the internal primers $(2 \mu \mathrm{l})$ and 25 $\mu 1$ Master mix in a $25 \mu 1$ reaction mixture. The cycling conditions were $95^{\circ} \mathrm{C}$ for $5 \mathrm{~min}$, 35 cycles of $95{ }^{\circ} \mathrm{C}$ for $30 \mathrm{sec}, 60^{\circ} \mathrm{C}$ for 45 sec, $72{ }^{\circ} \mathrm{C}$ for $60 \mathrm{sec}$ and a final extension of $72{ }^{\circ} \mathrm{C}$ for $10 \mathrm{~min}$. The PCR products were analyzed by electrophoresis using $1.5 \%$ trisborate-ethylenediaminetetraacetic acid (TBE) agarose gel containing SYBR Safe stain (Invitrogen, California, USA) and were visualized using a gel document system (BioRad, USA).

\section{Sequencing, phylogenetic analysis and genotyping}

Ten samples of successful PCR products of second-round amplification (Nested PCR) were sequenced by the Sanger method in both directions using an ABI PrismTM 3730 Genetic Analyzer (Applied Biosystems, Foster City, California, USA) from the Macrogen Company (Seoul, South Korea). The sequence analysis was performed using the Bioedit Sequence Alignment Editor 7.1.3.0. Genotype identification was accomplished by conducting a nucleotide similarity search in Basic Local Alignment Search Tool (BLAST) to search for the most similar reference sequences to the $T$. vaginalis sequence. Strains of T. vaginalis were recognized at the species level, based on $\geq 99 \%$ identity with the reference sequences, deposited in the Gene Bank under the accession numbers MW355756-MW355765. Phylogenetic analysis was performed using the MEGA software (version 7). The phylogenetic tree, of obtained Trichomonas genotypes from the present study together with sequences from Gene Bank, was constructed using the Maximum Likelihood method and Kimura 2-parameter model with bootstrap values (determined by 1000 replicates).

\section{Results}

Of the 1765 evaluated samples, 21 (1.18\%) were positive for $T$. vaginalis infection upon microscopic and molecular examination. Both morphological and molecular analyses indicated that $2.62 \%(13 / 495)$ of secretions of posterior vaginal fornix samples and $0.62 \%$ $(8 / 1270)$ of urine specimen samples were positive for $T$. vaginalis. The age of the infected women with $T$. vaginalis ranged from 15 to 50, however, the infection was more common in women between the ages of 25 and $34(47.6 \%)$. Next, we determined that the most common clinical symptom was cervical lesions (28.6\%), followed by patchy erythema $(23.8 \%)$ and vaginal discharge (19\%). Of the 21 infected women, one case $(4.76 \%)$ had a history of taking metronidazole, one case (4.76 $\%$ ) had a history of taking cefixime, and two cases $(9.52 \%)$ had a history of taking fluconazole. Also, no history of treatment was recorded in most of the patients (81\%). Abortion and preterm birth were reported in $9.52 \%$ and $4.76 \%$ of patients, respectively. About $62 \%$ of patients consumed contraceptive pills, $19 \%$ of patients used IUD (Intrauterine Device) and the remaining 19\% had no history of either forms of birth control (Table 1). Notably, all patients were married. The difference between trichomoniasis and age groups, clinical symptoms, history of abortion and prevention of pregnancy were not statistically significant ( $\mathrm{p}$ value> 0.5 ) (Table 2).

We successfully detected $T$. vaginalis in 21 urine and vaginal swab samples using Nested PCR. A single $1100 \mathrm{bp}$ product of the actin gene was amplified in all 21 samples, which was in agreement with the product size of $T$. vaginalis (Figure 1). Partial nucleotide sequences of $T$. vaginalis isolates using BLAST analysis with reference sequences in GenBank database showed that eight isolates 


\section{Alikhani M et al}

belonged to genotype $\mathrm{G}$, and two isolates belonged to genotype E (Figure 2). According to the phylogenetic tree, Tritrichomonas suis was considered the out-group branch (GenBank Accession no. AB4698092).

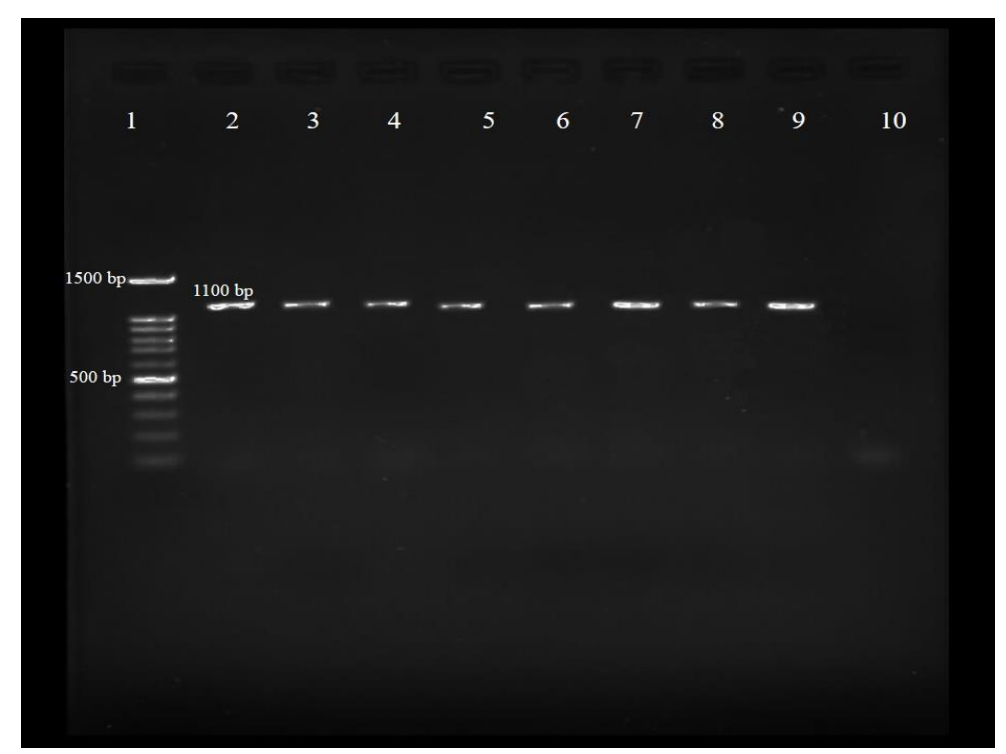

Fig. 1. Nested-PCR result of T. vaginalis isolates from women patients of Ilam city using actin gene. Line 1: 100 bp ladder marker, Lines $2-$ 8: Sample of patients (current study), Line 9: Positive control and Line 10: Negative control.

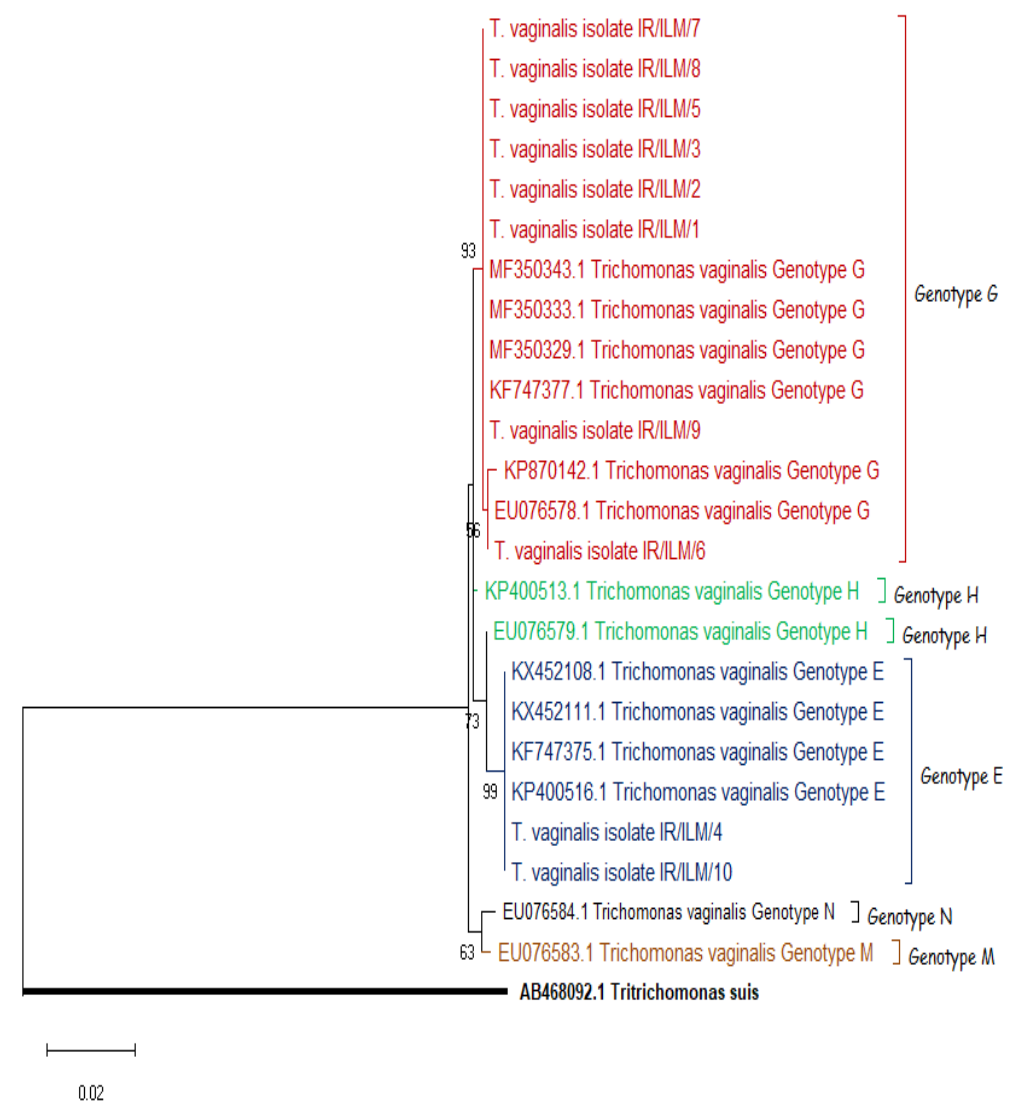

Fig. 2. Phylogenetic tree of actin gene sequences of $T$. vaginalis isolates constructed by the Maximum Likelihood method and Kimura 2-parameter model using Mega software (version7). Isolate or strain names are as provided in Genbank as available, followed by accession numbers in parentheses. Sequences generated in this study named as T. vaginalis IR/ILM. Trichomonas suis (accession number AB4698092) used as the out-group. Bootstrap values (\%) are indicated at the internal nodes (1000 replicates). Bootstrap values of less than $50 \%$ are not shown. 
Table 1. Data regarding the frequency of Trichomonas vaginalis isolated from positive patients in Ilam city, southwest Iran.

\begin{tabular}{lll}
\hline Demographic data & & Positive No. $(\%)$ \\
\hline \multirow{3}{*}{ Age } & $<15$ & $0(0)$ \\
& $15-24$ & $1(4.76)$ \\
& $25-34$ & $10(47.6)$ \\
& $35-44$ & $7(33.33)$ \\
& $44-49$ & $2(9.52)$ \\
& $\geq 50$ & $1(4.76)$ \\
\hline \multirow{2}{*}{ Clinical symptoms } & Gray color discharge & $1(4.76)$ \\
& Erythema and vaginal edema & $1(4.76)$ \\
& Patchy erythema & $5(23.8)$ \\
& cervical lesions & $6(28.6)$ \\
& White color discharge & $4(19)$ \\
& No symptoms & $4(19)$ \\
\hline \multirow{2}{*}{ Pregnancy outcome } & Yes & $4(19)$ \\
& No & $17(81)$ \\
\hline \multirow{2}{*}{ Prevention of pregnancy } & Abortion & $2(9.52)$ \\
& Death & $0(0)$ \\
& Preterm infant birth & $1(4.76)$ \\
& Normal infant birth & $17(81)$ \\
& No pregnancy & $1(4.76)$ \\
\hline & Condom & $0(0)$ \\
& Consumption of contraceptive pills & $13(62)$ \\
& IUD & $4(19)$ \\
& TL & $0(0)$ \\
& No Prevention & $4(19)$ \\
\hline
\end{tabular}

Table 2. Data regarding the frequency of Trichomonas vaginalis isolated from women specimens referred to health centers of Ilam city, southwest Iran.

\begin{tabular}{|c|c|c|c|c|c|}
\hline Demographic data & Total No. & Positive No. & \%Positive & Chi square & p value \\
\hline \multicolumn{6}{|l|}{ Age } \\
\hline$<15$ & 10 & 0 & 0 & \multirow{6}{*}{4.56} & \multirow[t]{6}{*}{0.47} \\
\hline $15-24$ & 249 & 1 & 0.4 & & \\
\hline $25-34$ & 593 & 10 & 1.69 & & \\
\hline $35-44$ & 445 & 7 & 1.57 & & \\
\hline $44-49$ & 363 & 2 & 0.55 & & \\
\hline$\geq 50$ & 105 & 1 & 0.9 & & \\
\hline \multicolumn{6}{|l|}{ Clinical symptoms } \\
\hline Gray color discharge & 184 & 1 & 0.54 & \multirow[t]{6}{*}{5.11} & \multirow[t]{6}{*}{0.41} \\
\hline Erythema and vaginal edema & 310 & 1 & 0.32 & & \\
\hline Patchy erythema & 219 & 5 & 12.28 & & \\
\hline cervical lesions & 442 & 6 & 1.36 & & \\
\hline White color discharge & 330 & 4 & 1.21 & & \\
\hline No symptoms & 280 & 4 & 1.43 & & \\
\hline \multicolumn{6}{|l|}{ Drug consumption } \\
\hline Yes & 144 & 4 & 2.78 & \multirow[t]{2}{*}{3.36} & \multirow[t]{2}{*}{0.06} \\
\hline No & 1621 & 17 & 1.05 & & \\
\hline \multicolumn{6}{|l|}{ Pregnancy outcome } \\
\hline Abortion & 105 & 2 & 1.9 & \multirow[t]{5}{*}{7.52} & \multirow[t]{5}{*}{0.11} \\
\hline Death & 7 & 0 & 0 & & \\
\hline Preterm infant birth & 73 & 1 & 1.37 & & \\
\hline Normal infant birth & 1015 & 17 & 1.67 & & \\
\hline No pregnancy & 565 & 1 & 0.18 & & \\
\hline \multicolumn{6}{|l|}{ Prevention of pregnancy } \\
\hline Condom & 207 & 0 & 0 & \multirow[t]{5}{*}{5.06} & \multirow[t]{5}{*}{0.28} \\
\hline Consumption of contraceptive pills & 842 & 13 & 1.54 & & \\
\hline IUD & 256 & 4 & 1.56 & & \\
\hline $\mathrm{TL}$ & 113 & 0 & 0 & & \\
\hline No Prevention & 347 & 4 & 1.15 & & \\
\hline
\end{tabular}




\section{Discussion}

Trichomoniasis is considered one of the most prevalent non-viral sexually transmitted infections worldwide. Most infections are asymptomatic and highly communicable between sexual partners $(20,21)$.

In accordance with our findings, similar prevalence rates were observed in other regions of Iran. We found that $21(1.18 \%)$ out of 1765 specimens were infected with $T$. vaginalis. A study that analyzed 1353 pap smears in women from Ahvaz city in southwest Iran, also reported similar findings where $1.4 \%$ of patients were infected with $T$. vaginalis (22). In Mazandaran, a province in northern Iran, PCR results showed that $0.48 \%$ of pregnant women referred to health centers were infected with $T$. vaginalis (23). The frequency distribution of $T$. vaginalis infection in Iran also varies (0.5\% to about 39\%) amongst different age groups of women and geographical location (24).

The incidence of $T$. vaginalis infection depends on several factors including socioeconomic status, poverty level, level of education and hygiene during sexual encounters, having multiple sexual partners, and high-risk sexual behaviors (25). Furthermore, selecting appropriate methods to evaluate the spread of this disease is important. One of the most sensitive diagnostic techniques for clinical samples taken from patients with trichomoniasis is Nested PCR (26).

We found the infection to be prevalent in women between the ages of 25 and 34 (47.6\%). This may be due to increased sexual contact or changes in the genital tract due to predisposing factors such as increasing age (27).

As demonstrated in our results, cervical lesions were the most common clinical symptom followed by patchy erythema and vaginal discharge. Similarly, a previous study confirmed that there is a significantly higher risk of developing cervical lesions in women exposed to T. vaginalis compared to those who were not exposed (28).

Trichomoniasis is a ping-pong disease. Since all 21 patients were married, their sexual partners may also be infected, and the prevalence of $T$. vaginalis should, therefore, be examined in these individuals (29). Subjects in the study who used condoms during sexual intercourse did not confer a $T$. vaginalis infection. Conversely, T. vaginalis is usually spread by having sex without a condom. Therefore, to prevent disease transmission, the use of condoms is highly recommended.

Drug resistance is a major concern for $T$. vaginalis infections and threatens current prevention treatments (30). Of the 21 positive trichomonas infections, four cases had a consumption history of metronidazole, cefixime, and fluconazole. With this in mind, drug resistance may play a role in the isolated samples, however, drug resistance and pathogenic aspects of $T$. vaginalis still remains to be fully elucidated. One factor that may contribute to $T$. vaginalis drug resistance is genetic diversity (30).

Genetic investigations can shed light on drug resistance, pathobiology, etiology and other features of epidemiology for $T$. vaginalis and the identification of critical genes (31). Various techniques have been used to identify and detect $T$. vaginalis including monoclonal antibody binding (32), antigenic characterization (33), PCR, random amplified polymorphic DNA (RAPD) (34), restriction fragment length polymorphisms (RFLP), Nested polymerase chain reaction (Nested PCR), and real-time PCR (35). The abovementioned techniques have been described as more sensitive compared to direct and culture methods (36). PCR is the preferred method in the diagnosis of trichomoniasis. Moreover, the actin gene can be used as a unique indicator owing to its structural role in organisms (10). Following the amplification of the actin gene, we found the most common genotypes to be $G$ and $\mathrm{E}$. This is consistent with the results of Hezarjaribi et al (23) who also used the actin gene to show that the genotypes G, E, and I were the predominant genotypes in women and men in northern Iran. Lastly, using PCRRFLP patterns, sequencing, and phylogenetic 
analyses, Spotin et al (37) found the most predominant genotypes in asymptomatic patients of Tabriz in northwest Iran to be $G$ (73.4\%) and $\mathrm{E}(26.6 \%)$.

In 2015, the five predominant actin genotypes exposed using PCR-RFLP in Kenya were E, N, G, I and P (38). Comparatively, the results of this study differed from Matini et al (39), where the genotype A was the most prevalent in women referred to gynecology clinics in western Iran. The genome of $T$. vaginalis is $160 \mathrm{Mb}$ consisting of approximately 60,000 protein-coding genes, where repeated and transposable nucleotide of the genome may explain the genetic diversity of $T$. vaginalis (40). The consequence of all investigations with regards to genotyping and phylogenetic examination of $T$. vaginalis shows that it is genetically diverse.

The prevalence of $T$. vaginalis infection

\section{References}

1. Rein MF. Trichomoniasis. Hunter's tropical medicine and emerging infectious diseases: Elsevier; 2020;731-733.

2. Menezes CB, Frasson AP, Tasca $T$. Trichomoniasis-are we giving the deserved attention to the most common non-viral sexually transmitted disease worldwide? Microbial cell. 2016;3(9):404-419.

3. Carrillo-Ávila JA, Serrano-García ML, Fernández-Parra J, Sorlózano-Puerto A, Navarro-Marí JM, Stensvold CR, et al. Prevalence and genetic diversity of Trichomonas vaginalis in the general population of Granada and co-infections with Gardnerella vaginalis and Candida species. J Med Microbiol. 2017;66(10):1436-1442.

4. Davey DJ, Shull H, Billings J, Wang D, Adachi K, Klausner J. Prevalence of curable sexually transmitted infections in pregnant women in low-and middle-income countries from 2010 to 2015: a systematic review. Sex Transm Dis. 2016;43(7):450-8.

5. Organization WHO. Global incidence and prevalence of selected curable sexually transmitted infections:2008. 2012; 20(40):207-208.

6. Hezarjaribi HZ, Fakhar M, Shokri A, Teshnizi SH, Sadough A, Taghavi M. was low in the city of Ilam city in southwest Iran and based on molecular findings, the main genotypes were $G$ and E. Here, we demonstrate that there is genotypic diversity in $T$. vaginalis clinical samples in women within this region. These results suggest that there may be genetic polymorphisms in the open reading frame (ORF) of the actin gene of $T$. vaginalis, thereby, making the actin gene a key genetic target for molecular epidemiology and genotyping of $T$. vaginalis.

\section{Acknowledgements}

Research reported in this publication was supported by Deputy of Research, Ilam University of Medical Sciences, Ilam, Iran. (Grant No 949006/148). The authors thank Ilam University of Medical Sciences, Ilam, Iran.

The authors declare that there is no conflict of interests.

Trichomonas vaginalis infection among Iranian general population of women: a systematic review and meta-analysis. Parasitol Res. 2015;114(4):1291-300.

7. Meade JC, Carlton JM. Genetic diversity in Trichomonas vaginalis. Sexually Transmitted Infections. 2013;89(6):444-8.

8. Swygard H, Sena A, Hobbs M, Cohen M. Trichomoniasis: clinical manifestations, diagnosis and management. Sex Transm Infect. 2004;80(2):91-95.

9. Krieger JN, Jenny C, Verdon M, Siegel N, Springwater R, Critchlow CW, et al. Clinical manifestations of trichomoniasis in men. Ann Intern Med. 1993;118(11):844-9.

10. Crucitti T, Abdellati S, Van Dyck E, Buvé A. Molecular typing of the actin gene of Trichomonas vaginalis isolates by PCRrestriction fragment length polymorphism. Clin Microbiol Infect. 2008;14(9):844-52.

11. Hernández H, Fraga J, Marcet R, Alba A, Figueredo M, Alfonso Y, et al. Genetic diversity of Trichomonas Vaginalis clinical isolates according to restriction fragment length polymorphism analysis of the $60-\mathrm{kDa}$ proteinase gene. Acta Parasitol. 2019;64(2):300-307. 
12. Squire DS, Lymbery AJ, Walters J, Brigg F, Paparini A, Thompson RA. Population structure and genetic diversity of Trichomonas vaginalis clinical isolates in Australia and Ghana. Infection, Genetics and Evolution. 2020:104318. 13. Demirağ S, Malatyalı E, Ertuğ S, Ertabaklar H. Determination of Trichomonas vaginalis Genotypes Using PCR-Restriction Fragment Length Polymorphism (RFLP). Turkiye Parazitol Derg. 2017;41(4):188-191.

14. Ertabaklar H, Ertuğ S, Çalışkan SÖ, Malatyalı E, Bozdoğan B. Use of Internal Transcribed Spacer Sequence Polymorphisms as a Method for Trichomonas vaginalis Genotyping. Turkiye Parazitol Derg. 2018;42(1):6-10.

15. Ahmadi MH, Amirizadeh N, Rabiee M, Rahimi-Sharbaf F, Pourfathollah AA. Noninvasive Fetal Sex Determination by RealTime PCR and TaqMan Probes. Rep Biochem Mol Biol. 2020;9(3):315-323.

16. Liu J, Feng M, Wang X, Fu Y, Ma C, Cheng $\mathrm{X}$. Unique Trichomonas vaginalis gene sequences identified in multinational regions of Northwest China. Biosci Trends. 2017;11(3):303-307.

17. Mercer F, Johnson PJ. Trichomonas vaginalis: Pathogenesis, symbiont interactions, and host cell immune responses. Trends Parasitol. 2018;34(8):683-693.

18. Momeni Z, Sadraei J, Kazemi B, Dalimi A. Molecular typing of the actin gene of Trichomonas vaginalis isolates by PCR-RFLP in Iran. Exp Parasitol. 2015;159:259-63.

19. Hezarjaribi HZ, Taghavi M, Fakhar M, Gholami S. Direct diagnosis of Trichomonas vaginalis infection on archived pap smears using Nested PCR. Acta Cytol. 2015;59(1):104-8.

20. Mavedzenge SN, Van Der Pol B, Cheng H, Montgomery ET, Blanchard K, de Bruyn G, et al. Epidemiological synergy of Trichomonas vaginalis and HIV in Zimbabwean and South African women. Sex Transm Dis. 2010;37(7):460-6.

21. Apalata T, Carr WH, Sturm WA, LongoMbenza B, Moodley P. Determinants of symptomatic vulvovaginal candidiasis among human immunodeficiency virus type 1 infected women in rural Kwazulu-natal, South Africa. Infect Dis Obstet Gynecol. 2014;2014:387070.

22. Makvandi S, Zargar Shoushtari S. The relationship of cervicovaginal infections in pap smear samples with some factors in Ahvaz, Iran; an epidemiological study. Jundishapur Journal of Chronic Disease Care. 2012;1(1):55-61.

23. Ziaei Hezarjaribi H, Taghavi M, Faridnia R, Kalani H, Mardani A, Jorjani O, et al. Actin Gene-Based Molecular Typing of Trichomonas vaginalis Clinical Isolates from the North of Iran. Acta Parasitol. 2020;65(4):859-864.

24. Khalili B, Ghasemi-Dehkordi P, Pourshahbazi G, Yousofi-Darani H, Hashemzadeh-Chaleshtori M, Doosti A. Genotyping of Trichomonas vaginalis isolates from women in Shahrekord city (Southwestern Iran). Genetika. 2017;49(3):1059-1070.

25. Arbabi M, Delavari M, Fakhrieh-Kashan Z, Hooshyar H. Review of trichomonas vaginalis in Iran, based on epidemiological situation. $\mathbf{J}$ Reprod Infertil. 2018;19(2):82-88.

26. Nwuba R, Evbuomwan I, Olasunkanmi B, Odukogbe A. Comparative Evaluation of Microscopy and Polymerase Chain Reaction Sensitivity in the Diagnosis of Trichomonas vaginalis Using Vaginal Swab Samples from Women in Ibadan, Oyo State, Nigeria. NISEB Journal. 2019;17(2).

27. Nourian A, Shabani N, Fazaeli A, Mousavinasab SN. Prevalence of Trichomonas vaginalis in pregnant women in Zanjan, Northwest of Iran. Jundishapur J Microbiol. 2013;6(8):e7258.

28. Su R-Y, Ho L-J, Yang H-Y, Chung C-H, Yang S-S, Cheng C-Y, et al. Association between Trichomonas vaginalis infection and cervical lesions: a population-based, nested casecontrol study in Taiwan. Parasitol Res. 2020;119(8):2649-2657.

29. Schwebke JR, Gaydos CA, Davis T, Marrazzo J, Furgerson D, Taylor S, et al. Clinical evaluation of the Cepheid Xpert TV assay for detection of Trichomonas vaginalis with prospectively collected specimens from men and women. J Clin Microbiol. 2018;56(2):e01091-17.

30. Bradic M, Warring SD, Tooley GE, Scheid $\mathrm{P}$, Secor WE, Land KM, et al. Genetic indicators 
of drug resistance in the highly repetitive genome of Trichomonas vaginalis. Genome Biol Evol. 2017;9(6):1658-1672.

31. Abou-kamar W, Abdel-Mageid A, El-Nahas H, Atia R, El-Tantawy N. Genetic relatedness of Trichomonas vaginalis isolates to the clinical variability. iMedPub Journals. 2017;1(1):103.

32. Vaca GBB. Topical Use of Monoclonal Antibodies as a Multipurpose Prevention Technology Offering Contraception and Decreased Transmission of HIV-1 and Trichomonas vaginalis: Boston University; 2020.

33. Zhang Z, Li Y, Wang S, Hao L, Zhu Y, Li $\mathrm{H}$, et al. The Molecular Characterization and Immunity Identification of Trichomonas vaginalis Adhesion Protein 33 (AP33). Front Microbiol. 2020;11:1433.

34. Kaul P, Gupta I, Sehgal R, Malla N. Trichomonas vaginalis: random amplified polymorphic DNA analysis of isolates from symptomatic and asymptomatic women in India. Parasitol Int. 2004;53(3):255-62.

35. Margarita V, Marongiu A, Diaz N, Dessì D, Fiori PL, Rappelli P. Prevalence of doublestranded RNA virus in Trichomonas vaginalis isolated in Italy and association with the symbiont Mycoplasma hominis. Parasitol Res. 2019;118(12):3565-3570.
36. Nye MB, Schwebke JR, Body BA. Comparison of APTIMA Trichomonas vaginalis transcription-mediated amplification to wet mount microscopy, culture, and polymerase chain reaction for diagnosis of trichomoniasis in men and women. Am J Obstet Gynecol. 2009;200(2):188.e1-7.

37. Spotin A, Eghtedar ST, Shahbazi A, Salehpour A, Sarafraz S, Shariatzadeh SA, et al. Molecular Characterization of Trichomonas vaginalis strains based on identifying their probable variations in asymptomatic patients. Iran J Parasitol. 2016;11(4):507-514.

38. Masha SC, Cools P, Crucitti T, Sanders EJ, Vaneechoutte M. Molecular typing of Trichomonas vaginalis isolates by actin gene sequence analysis and carriage of $T$. vaginalis viruses. Parasit Vectors. 2017;10(1):537.

39. Matini M, Rezaeian M, Mohebali M, Maghsood A, Rabiee S, Rahimi-Foroushani A, et al. Genotyping of Trichomonas vaginalis isolates in Iran by using single stranded conformational polymorphism-PCR technique and internal transcribed spacer regions. Trop Biomed. 2012;29(4):605-12.

40. Carlton JM, Hirt RP, Silva JC, Delcher AL, Schatz M, Zhao Q, et al. Draft genome sequence of the sexually transmitted pathogen Trichomonas vaginalis. Science. 2007;315(5809):207-12. 